\section{Let us spend time pitchside for our athletes' benefit: a call to broaden collaboration by Sport and Exercise Medicine Switzerland (SEMS)}

\author{
Philippe Matthias Tscholl (1) 1,2,3
}

Bringing athletes to their peak and keeping them performing at that level requires many factors, such as talent, persistence, eagerness, as well as excellent collaboration and communication among the coaching, technical and medical staff. The various professionals (coaches, advisors, health professionals) who serve the athlete may have different visions of how to pursue the common goal of success-especially with respect to player health. Whether the issue is an injury, illness, or a plan to prevent injuries/illness, the medical team might be challenged by the often short-term performance goals of the technical staff and coaches (and also the athlete). These goals (long-term health, a long career vs immediate performance) can be at odds.

We clinicians have a duty to protect the athlete's health but situations may arise immediately prior or throughout the season that require reasonable compromise in the treatment of the athlete as some sport-specific training load must be maintained. Last year, Sweden's Professor Jan Ekstrand and colleagues $^{1}$ reported that poor interpersonal relations and conflict within the technical and medical staff correlated with higher risk of injury and a lower availability of athletes for training and matches. Therefore, a culture of high professional competence, mutual understanding, communication and trust must be established.

\section{INTERDISCIPLINARY COLLABORATION}

Promoting collaboration and sharing understanding is a mainstay of Sport \& Exercise

\footnotetext{
'Department of Orthopaedic Surgery and Traumatology, Geneva University Hospitals, Geneva, Switzerland ${ }^{2}$ ReFORM (Reseau Francophone Olympique de la Recherche en Médecine du Sport), IOC Research Centre for Prevention of Injury and Protection of Athlete Health ${ }^{3}$ Sport \& Exercise Medicine, Switzerland
}

Correspondence to Dr Philippe Matthias Tscholl, Department of Orthopaedic Surgery and Traumatology, Geneva University Hospitals, Geneva, Switzerland; ph.tscholl@sunrise.ch

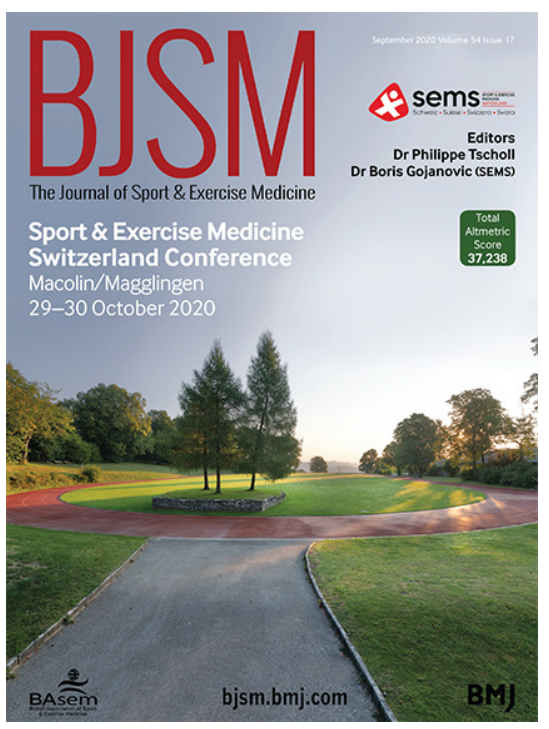

Medicine Switzerland (SEMS). In 2018, the Annual Congress of what was then called the Swiss Sports Medicine Society (now SEMS) was organised in partnership with the Swiss Sports Physiotherapy Association. This was a great success by all accounts for the over 750 participants. True to Henry Ford's quote of 'getting together is a start, sticking together is progress, and working together is a success', this year's SEMS congress from 29 to 30 October 2020 will take place in Magglingen, close to the Swiss capital Berne. Magglingen hosts the Swiss federal office of sport, the Swiss Federal School of Sport and the Sports Coach Education Switzerland-it is the educational centre of sports performance and coaching. The congress will focus on exercise physiology, sports nutrition, overuse injuries and the interdisciplinary collaboration for the best of our athletes.

\section{EARNING TRUST-THE INTERNET IS NOT THE ENEMY}

When dealing with an injury, high-level athletes are very sensitive to disagreement within the off-field team (health professionals and coaches), and they are quick to seek a second opinion. They may not limit themselves to physician/physiotherapist opinions-seeking advice from other team members or the internet is common. Read Sara Riggare's discussion of the 'internet-positive patient' or 'e-patient' in this issue (see page 1064). Such a patient is not necessarily a burden for the physician, nor is searching the internet proof of distrust. $^{2}$ A well-informed, cooperative patient often complies well with a treatment plan and is often very motivated to improve their health status. Clear, sincere and non-ambiguous information transfer, elucidation and an open discussion about the different sources of the worldwide web are essential for the healthy athlete/patient-doctor relationship.

\section{TEAMWORK AMONG TECHNICAL AND MEDICAL STAFF-A KEY FOR ATHLETE SUCCESS}

In this Swiss issue of BJSM, Akerlund et al (see page 1028) and Pas et al (see page 1036) show that collaboration and personal interaction are critical for health promotion in athletes. An e-health tennis-specific injuryprevention programme in Netherlands, which was devoid of personal or individual interaction throughout the study period, had a low compliance rate and did not lead to health benefits. In contrast, a structured prevention exercise programme for adolescent floorball players in Sweden, implemented by coaches and further reinforced by the study team reduced injury incidence. There are numerous differences between the studies but I opine that these important studies point to the importance of teamwork among the technical and medical staff to promote athlete success.

Sport and exercise medicine physicians who aim to provide the best care in case of injury or illness, or introduce a prevention programme for their athletes, belong not only in the office but need to spend time pitchside. Sport-specific knowledge and team internal group dynamics are integral part of excellent communication and collaboration that are essential for us to serve athletes very well.

Contributors Designing and writing of the manuscript has been performed by the single author.

Funding The authors have not declared a specific grant for this research from any funding agency in the public, commercial or not-for-profit sectors.

Competing interests None declared.

Patient consent for publication Not required.

Provenance and peer review Commissioned; internally peer reviewed. 


\section{Warm up}

(c) Author(s) (or their employer(s)) 2020. No commercial re-use. See rights and permissions. Published by BMJ.

\section{(D) Check for updates}

To cite Tscholl PM. Br J Sports Med 2020:54:1013-1014.
Accepted 7 July 2020

Br J Sports Med 2020:54:1013-1014. doi:10.1136/bjsports-2020-103002

\section{ORCID iD}

Philippe Matthias Tscholl http://orcid.org/0000-00031702-7114

\section{REFERENCES}

1 Ekstrand J, Lundqvist D, Davison M, et al. Communication quality between the medical team and the head coach/ manager is associated with injury burden and player availability in elite football clubs. Br J Sports Med 2019;53:304-8.

2 Riggare S. E-patients hold key to the future of healthcare. BMJ 2018;360:k846. 